\title{
Corrigendum: Rapid Eye Movements in Sleep Furnish a Unique Probe Into Consciousness
}

\author{
Charles C.-H. Hong ${ }^{1,2 *}$, James H. Fallon ${ }^{3,4}$, Karl J. Friston ${ }^{5}$ and James C. Harris ${ }^{2}$ \\ ${ }^{1}$ Patuxent Institution, Correctional Mental Health Center - Jessup, Jessup, MD, United States, ${ }^{2}$ Department of Psychiatry \\ and Behavioral Sciences, The Johns Hopkins Hospital, Baltimore, MD, United States, ${ }^{3}$ Department of Anatomy and \\ Neurobiology, University of California, IIvine, IIvine, CA, United States, ${ }^{4}$ Department of Psychiatry and Human Behavior, \\ University of California, Irvine, Irvine, CA, United States, ${ }^{5}$ The Wellcome Trust Centre for Neuroimaging, Institute of Neurology, \\ University College London, London, United Kingdom
}

Keywords: predictive coding, dream, rapid eye movements (REMs) in sleep, autism, visual perception, retrosplenial cortex, claustrum, thalamic reticular nucleus

\section{A Corrigendum on}

Rapid Eye Movements in Sleep Furnish a Unique Probe Into Consciousness by Hong, C. C.-H., Fallon, J. H., Friston, K. J., and Harris, J. C. (2018). Front. Psychol. 9:2087. doi: $10.3389 /$ fpsyg.2018.02087

In the original article, there was an error. Crucially, fMRI correlates of REMs timed with EOG (Wehrle et al., 2005; Miyauchi et al., 2009) are similar to those with video-timing and have been construed as empirical support for predictive coding (Hobson et al., 2014).

A correction has been made to the first paragraph of the Sub-section Video-Timing Findings Lend Support to Predictive Coding.

Crucially, fMRI correlates of REMs timed with EOG (Wehrle et al., 2005; Miyauchi et al., 2009) are similar to those with video-timing. However, it is our new findings in the video-timed study (Hong et al., 2009) that are construed as empirical support for predictive coding (Hobson et al., 2014).

The authors apologize for this error and state that this does not change the scientific conclusions of the article in any way. The original article has been updated.

${ }^{*}$ Correspondence:

Charles C.-H. Hong charleschhong@gmail.com

Specialty section

This article was submitted to Theoretical and Philosophical Psychology,

a section of the journal Frontiers in Psychology

Received: 15 November 2018 Accepted: 23 November 2018 Published: 10 December 2018

Citation: Hong CC-H, Fallon JH, Friston KJ and Harris JC (2018) Corrigendum: Rapid Eye Movements in Sleep Furnish a Unique Probe Into Consciousness.

Front. Psychol. 9:2493. doi: 10.3389/fpsyg.2018.02493

\section{REFERENCES}

Hobson, J. A., Hong, C. C. H., and Friston, K. (2014). Virtual reality and consciousness inference in dreaming. Front. Psychol. 5:1133. doi: 10.3389/fpsyg.2014.01133

Hong, C. C. H., Harris, J. C., Pearlson, G. D., Kim, J. S., Calhoun, V. D., Fallon, J. H., et al. (2009). fMRI evidence for multisensory recruitment associated with rapid eye movements during sleep. Hum. Brain Mapp. 30, 1705-1722. doi: $10.1002 / \mathrm{hbm} .20635$

Miyauchi, S., Misaki, M., Kan, S., Fukunaga, T., and Koike, T. (2009). Human brain activity time-locked to rapid eye movements during REM sleep. Exp. Brain Res. 192, 657-667. doi: 10.1007/s00221-008-1579-2

Wehrle, R., Czisch, M., Kaufmann, C., Wetter, T. C., Holsboer, F., Auer, D. P., et al. (2005). Rapid eye movementrelated brain activation in human sleep: a functional magnetic resonance imaging study. Neuroreport 16, 853-857. doi: 10.1097/00001756-200505310-00015

Conflict of Interest Statement: The authors declare that the research was conducted in the absence of any commercial or financial relationships that could be construed as a potential conflict of interest.

Copyright (c) 2018 Hong, Fallon, Friston and Harris. This is an open-access article distributed under the terms of the Creative Commons Attribution License (CC BY). The use, distribution or reproduction in other forums is permitted, provided the original author(s) and the copyright owner(s) are credited and that the original publication in this journal is cited, in accordance with accepted academic practice. No use, distribution or reproduction is permitted which does not comply with these terms. 